\title{
Alterations in Intestinal Uptake and Compartmentalization of Zinc in Response to Short-Term Dexamethasone Therapy or Excess Dietary Zinc in Piglets
}

\author{
ZHENG WANG, STEPHANIE A. ATKINSON, ROBERT F. P. BERTOLO. \\ STAFFAN POLBERGER. AND BO LONNERDAL \\ Department of Pediatrics. 1/.17aster Lniversity: Hamilton. Ontario, Canada L8N3Z5 /Z.W.. S.A.A.. R.F.P.B.]: \\ and Department of Nutrition. University of California, Davis, California 95616 /S.P.. B.L.]
}

\begin{abstract}
Premature infants receive high dietary zinc and often glucocorticoids as a treatment for chronic lung disease. A piglet model was developed to investigate intestinal zinc transport and distribution of tissue zinc in response to treatment with short-term $(5 \mathrm{~d})$ glucocorticoid therapy or a high zinc diet. Piglets (13-15 d old; $n=21)$ were randomly allocated to: 1 ) dexamethasone (DEX) therapy $(1.5 \mathrm{mg} / \mathrm{kg}$ intramuscularly twice a day $), 2) \mathrm{high}$ zinc diet $(15.3 \mathrm{mmol} / \mathrm{kg})$, or 3$)$ control group $(0.3 \mathrm{mmol}$ dietary zinc/kg and saline intramuscularly twice a day). Pig weight, formula intake, urine volume, and blood glucose were monitored. At necropsy, tissue samples were obtained to measure zinc in plasma and zinc and metallothionein in liver and small intestinal mucosa. Velocity of zinc uptake by intestinal brush border membrane vesicles was measured using ${ }^{65} \mathrm{Zn}$ tracer. Maximum uptake rate and $\mathrm{Km}$ for zinc uptake by brush border membrane vesicles were significantly greater $(p<0.05)$ in DEX compared with control and high zinc groups. DEX-treated piglets had a significantly lower $(p<0.05)$ zinc efflux rate across brush border membrane vesicles compared with that of the control. The high zinc group had a higher liver $(p<0.05)$ and mucosal $(p<0.05)$ zinc content and higher liver metallothionein concentration $(p<0.001)$ compared with the control and DEX groups. Weight gain over $5 \mathrm{~d}$ was not different among groups. Daily blood glucose was higher $(p<0.05)$ in DEX versus control and high zinc groups. Short-term DEX treatment induced changes in mucosal uptake of zinc that are consistent with up-regulation of specific mucosal proteins, but this was not the case with metallothionein. These alterations in zinc metabolism may have consequences for zinc status in premature infants who receive glucocorticoids such as DEX and/or high zinc diets. (Pediatr Res 33: 118 -
\end{abstract} 124, 1993)

\section{Abbreviations}

LBW, low birth weight

DEX, dexamethasone

MT, metallothionein

BBMV, brush border membrane vesicle

$\mathbf{J}_{\max }$, maximum uptake rate

Received April 20. 1992: accepted October 1. 1992.

Correspondence and reprint requests: Dr. Stephanie A. Atkinson. Associate Professor, Department of Pediatrics. 3V42, McMaster University, 1200 Main Street West. Hamilton, Ontario L8N 3Z5, Canada.

Supported by a grant from the Medical Research Council of Canada (MA 8663). Dr. Atkinson holds a Career Scientist Award at McMaster University from the Ministry of Health of Ontario.
HEPES, $N$-2-hydroxyethylpiperazine- $N^{\prime}$-2-ethanesulfonic acid

PG, prostaglandin

FPLC, fast protein liquid chromatography

In very premature infants at risk of severe lung disease, medical management often includes use of glucocorticoid therapy and high zinc diets from mineral-fortified premature formulas. DEX. a synthetic glucocorticoid, is documented to stimulate lung maturation, thereby reducing the incidence and/or severity of severe lung disease in LBW infants (1-3). Prematurely born infants are particularly vulnerable to zinc deficiency because of limited zinc stores at birth (4) and malabsorption as a result of an immature gastrointestinal tract (5). Negative zinc balances have been documented in LBW infants fed breast milk or preterm formula containing five times the amount of zinc in breast milk (6). From animal studies, it is apparent that DEX, especially in combination with a relatively high zinc diet. may have a significant impact on intestinal zinc transport and hepatic storage (7-9).

Glucocorticoid hormones and exogenous (dietary) zinc have been implicated in the regulation of zinc homeostasis principally via induction of the major cytosolic zinc-binding protein MT (9). Tissue-specific induction of MT synthesis has been associated with reduced zinc absorption (10), decreased plasma zinc, and enhanced zinc accumulation in liver (11). Other studies in adult rats have shown increased zinc absorption across intestinal cells after glucocorticoid treatment (12,13). High levels of dietary zinc may induce gene expression of MT in intestinal mucosal and hepatic cells (9). The increased MT synthesis correlated with a reduction in overall zinc absorption in mature rodents (14). Little is known, however, about the effects of DEX or high dietary zinc during the newborn period.

Due to the physiologic and anatomical similarities of the digestive tract, the piglet is a good model for absorption studies in human LBW infants (15). To investigate the possible consequences of short-term exogenous DEX or high dietary zinc on zinc homeostasis during early development of LBW infants, we have established an early weaned piglet model.

\section{MATERIALS AND METHODS}

Animals. Ten- to 12-d-old male piglets were removed from the sow at the Arkell Research Farm (Guelph, Ontario, Canada) and brought to the McMaster University Central Animal Facility. The care of the piglets in this study conformed with the (ituide for the Care and Use of Experimental Animals (16). They were 
housed in stainless steel metabolic cages under infrared heat lamps used to maintain an ambient temperature of $30^{\circ} \mathrm{C}$. The piglets were weaned onto a specially designed liquid formula that has been used in our laboratory previously (Atkinson SA, Shah JK, Webber CE, Gibson IL, Gibson RS, unpublished manuscript). On the 1 st, 2 nd, and 3 rd d after arrival, the piglets were fed half-strength, 3/4-strength, and full-strength formula, respectively. Afterwards, they were fed full-strength formula. Piglets were weighed in the morning on arrival and on d 1, 3, and 5 of the study.

After an adaptation period of 3 to $4 \mathrm{~d}$, the early weaned piglets were randomly allocated to the control, high zinc, or DEXtreated group. They were fed $400 \mathrm{~mL}$ of formula $/ \mathrm{kg} \cdot \mathrm{d}^{-1}$ (quarter rations at 0900 and $1500 \mathrm{~h}$ and a half ration at $2100 \mathrm{~h}$ ) $[0.3$ $\mathrm{mmol}(18 \mathrm{mg}) / \mathrm{kg}$ zinc] for the study period of $5 \mathrm{~d}$. The high zinc group was fed formula containing zinc at a concentration of $15.3 \mathrm{mmol}(1000 \mathrm{mg}) / \mathrm{kg}$ dry weight of diet (zinc added as $\mathrm{ZnSO}_{4}$ to the vitamin/mineral mix). The DEX-treated group was injected intramuscularly twice a day with $1.5 \mathrm{mg} / \mathrm{kg}$ of DEX (sodium phosphate salt, Hexadrol, Organon Teknika, Toronto, Ontario, Canada) at 0900 and $2100 \mathrm{~h}$. The control and high zinc piglets received a volume-equivalent placebo injection of saline.

Because DEX-treated infants are known to become hyperglycemic, the blood glucose status of the piglets was assessed (18). Blood glucose was measured each morning before dosing and feeding by using Chemstrip BG (Boehringer-Mannheim, Laval, Quebec, Canada) on a drop of blood from a pin prick of an ear vein. Daily urine volumes were also measured to monitor glucose losses.

Blood and tissue samples. The piglets were killed on the morning of the 6th $\mathrm{d}$ of the study by a lethal injection. Fasted blood samples were taken by a heart puncture and urine samples by a bladder puncture. Plasma was retrieved by using heparinized syringes to draw the blood and by subsequent centrifugation at $2000 \times g$ for $15 \mathrm{~min}$. Final urine-glucose values were measured using a modified peroxidase-glucose oxidase assay from Dahlqvist (19).

One hundred $\mathrm{cm}$ of the proximal, medial, and distal small intestine were excised at necropsy and immediately immersed in ice-cold $0.9 \%$ saline. The intestine was slit lengthwise and then flushed with saline. Epithelial mucosa was scraped from the muscle tissue with a glass slide and stored at $-70^{\circ} \mathrm{C}$ for additional preparation. Scraping was performed on ice to minimize enzymatic activity. Samples of liver were also removed from the animals.

Preparation of $B B M V$. BBMV were obtained by homogenizing individual mucosal scrapings from each piglet and using a differential centrifugation method (20). The extent of brush border purification was determined by measuring changes in the sp act of sucrase (19). The BBMV solution was used in the ${ }^{65} \mathrm{Zn}$ transport study on the same day to avoid vesicle damage caused by freezing and thawing. All zinc uptake data represent mean values for two separate membrane preparations for each pig.

Zinc uptake experiments. A modification of the technique of Menard and Cousins (21) was used to perform transport experiments. Approximately $100 \mu \mathrm{g}$ of vesicular protein and an incubation buffer containing $300 \mathrm{mM}$ D-mannitol and $10 \mathrm{mM}$ TrisHEPES at $\mathrm{pH} 6.7$ with a total volume of $50 \mu \mathrm{L}$ were added to a test tube containing $50 \mu \mathrm{L}$ of the same buffer but containing increasing $\mathrm{ZnCl}_{2}$ concentrations $(0.1$ to $1.0 \mathrm{mM})$ and $1 \mu \mathrm{Ci}^{65} \mathrm{Zn}$. To develop the method for piglet intestinal tissue, the uptake study was performed at increasing incubation times $(0.25$ to 20 min) with constant $\mathrm{Zn}^{2+}$ concentration $(0.2 \mathrm{mM})$. The time curve (Fig. 1) showed that zinc uptake was saturated at about 10 min with an extravesicular zinc concentration of $0.2 \mathrm{mM}$, which suggested that $1 \mathrm{~min}$ of incubation should be appropriate to determine the initial rate of zinc uptake by BBMV. The saturable activity of the transport protein (Fig. 1) was also assessed from this experiment, thereby verifying the method. The uptake study was performed using BBMV concentrations as the changing

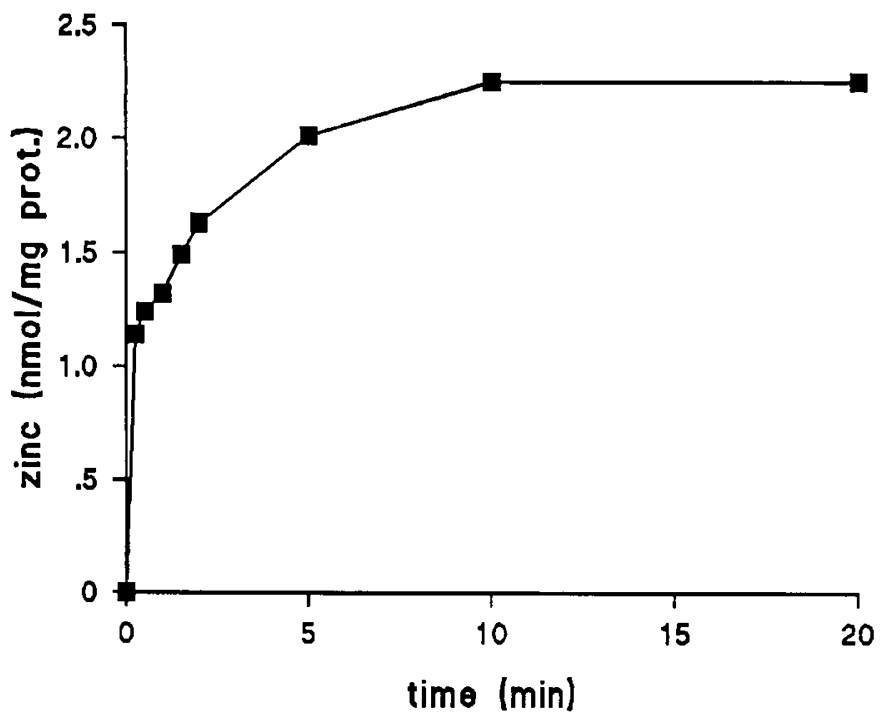

Fig. 1. Rates of zinc uptake by BBMV expressed as a function of time ranging from 0.25 to $20 \mathrm{~min}$. Zinc concentration of the medium was kept constant at $0.2 \mathrm{mM}$. The BBMV were recovered from an untreated piglet not involved in this study.

variable. $\mathrm{Zn}^{2+}$ concentration $(0.2 \mathrm{mM})$ and incubation time (1 min) were held constant while BBMV concentrations were increased from 0.3 to $11 \mathrm{mg}$ protein $\cdot \mathrm{mL}^{-1}$. The dependence of zinc transport on incubation temperature was also assessed. From these studies, it was determined that a carrier-mediated mechanism was involved in zinc transport.

After a 1 -min incubation at $37^{\circ} \mathrm{C}$, uptake was terminated with $1 \mathrm{~mL}$ of ice-cold stop solution $(300 \mathrm{mM}$ D-mannitol, $10 \mathrm{mM}$ Tris-HEPES, $\mathrm{pH}$ 6.7). The BBMV were collected on $0.22-\mu \mathrm{m}$ filters (Millipore, Groton, CT) using vacuum. The filters were rinsed twice more with stop solution to ensure quantitative collection of the vesicles. The filters were assayed for radioactivity by a gamma counter (Beckman Gamma 5500, Beckman Instruments, Irvine, CA). Samples were prepared in triplicate with a blank of nonspecific binding (no BBMV) included to correct for background radioactivity. To determine the binding of zinc to BBMV, we compared zinc transport kinetics between preparations treated with isotonic $(300 \mathrm{mM}$ D-mannitol, $10 \mathrm{mM}$ TrisHEPES, pH 6.7) or hypotonic $(0.1 \mathrm{mM}$ Tris-HEPES, $\mathrm{pH} 6.7)$ termination solutions. The decreased isotope retention with the hypotonic wash solution indicated that $\mathrm{Zn}$ uptake reflects predominantly intravesicular accumulation rather than binding to the BBMV.

Uptake rates were expressed as $\mathrm{nmol} \mathrm{Zn}^{2+}$ per $\mathrm{mg}$ total vesicular protein per min. Total protein was measured by the dyebinding procedure of Bradford (22) using crystalline BSA as a standard. The mean between batch precision for protein determination was $4.3 \pm 0.7 \%$ (coefficient of variation). $\mathrm{J}_{\max }$ and the half saturation constant $(\mathrm{Km})$ were determined using the method described by Eadie (23) and Hofstee (24). The Eadie-Hofstee plot is considered the best technique for rectangular hyperbola analysis $(25)$.

Zinc efflux across $B B M V$. To compare the permeability of BBMV between DEX-treated and control piglets, we measured the rate of zinc efflux across BBMV. BBMV was first loaded with ${ }^{65} \mathrm{Zn}$ via incubation with $0.3 \mathrm{mM} \mathrm{ZnCl}_{2}$ and $2 \mu \mathrm{Ci}^{65} \mathrm{Zn}$ in the incubation buffer at $37^{\circ} \mathrm{C}$ for $60 \mathrm{~min}$. After examining the amount of zinc loaded in BBMV, the incubation solution was diluted 19-fold with transport buffer ( $10 \mathrm{mM}$ Tris-HEPES, 300 mM D-mannitol, pH 6.7) containing 10 mM EGTA. At different time intervals after the dilution, the percentage of ${ }^{65} \mathrm{Zn}$ remaining in BBMV was determined by rapid filtration and counting of filters in a gamma counter (Beckman Gamma 550). Incubation was also performed at $4^{\circ} \mathrm{C}$ and $37^{\circ} \mathrm{C}$ for $60 \mathrm{~min}$ to determine 
whether BBMV zinc loading occurred via active uptake or passive diffusion and binding to the membrane.

Tissue zinc content. Zinc levels in plasma were measured using an atomic absorption spectrophotometer (model 703, PerkinElmer, Norwalk, CT) after a 5:1 dilution with $1.25 \mathrm{M}$ nitric acid (26). Certified standard reference plasma (A67 and A69; Interlaboratory Comparison Program, Centre de Toxicologie du Quebec, Sainte-Foy, Quebec, Canada) was used as a control throughout assay procedures. The zinc concentrations of the standard reference samples were determined to be 19.0 and $17.5 \mu \mathrm{M}$ compared with known values of 18.35 and $17.5 \mu \mathrm{M}$, respectively.

Liver and mucosal tissue samples were quantitatively assayed for zinc by atomic absorption spectrophotometry (Perkin-Elmer) (26). These tissue samples were prepared by weighing approximately $0.5 \mathrm{~g}$ of wet mucosa and approximately $1.0 \mathrm{~g}$ of wet liver into crucibles that were heated at $100^{\circ} \mathrm{C}$ for $24 \mathrm{~h}$ in a muffle furnace and then weighed dry. The samples were then heated at $500^{\circ} \mathrm{C}$ for $72 \mathrm{~h}$ and dissolved in $10 \mathrm{~mL} 1.25 \mathrm{M}$ nitric acid. The liver solutions were diluted $5: 1$ with a $1.25 \mathrm{M}$ nitric acid. Certified standard reference nonfat milk powder (National Bureau of Standards, Washington, DC, no. 1549) was analyzed. Zinc concentration for this reference material was $47.2 \pm 1.4 \mu \mathrm{g} / \mathrm{g}$ dry weight (coefficient of variation $=2.9 \%$ ) compared with the known value of $46.1 \pm 2.2 \mu \mathrm{g} / \mathrm{g}$ dry weight. Tissue zinc data were expressed as $\mu \mathrm{g}$ zinc/g dry weight.

Tissue MT concentration. MT levels were determined in liver and intestinal mucosa of all pigs. Tissue homogenates $(20 \% \mathrm{wt} /$ vol) were centrifuged at $10000 \times g$ for $20 \mathrm{~min}$ at $4^{\circ} \mathrm{C}$. The supernatant was heated for $2 \mathrm{~min}$ in a boiling water bath. After another $10000 \times g$ centrifugation for $2 \mathrm{~min}, 100 \mu \mathrm{L}$ of the supernatant was subjected to MT measurement by a cadmium binding assay using ${ }^{109} \mathrm{Cd}(27)$.

Intestinal mucosal zinc and copper binding proteins by FPLC. To study the effects of DEX and high zinc feeding on zinc and copper binding proteins in intestinal mucosa, the mucosal homogenate was analyzed by a FPLC system. Mucosa samples were homogenized in $20 \mathrm{mM}$ HEPES-PBS buffer, pH 7.4 (20\% wt/ vol), in a Janke \& Kunkel homogenizer (Tekmar Co., Staufen, Germany) in two 20-s intervals at medium speed. The homogenate was centrifuged at $169000 \times g$ at $4^{\circ} \mathrm{C}$ for $30 \mathrm{~min}$. A 500 $\mu \mathrm{L}$ aliquot of the supernatant was transferred to a Superose 12 column $(10 \times 300 \mathrm{~mm})$ of an FPLC system (Pharmacia, Uppsala, Sweden, model LCC-500). The eluting solution was $20 \mathrm{mM}$ HEPES-PBS, pH 7.4, and flow rate was $60 \mathrm{~mL} / \mathrm{h}$. The eluting fractions were collected at $1-\mathrm{min}$ intervals and analyzed by atomic absorption spectrophotometry for zinc and copper concentrations.

Brush border enzyme activity. Approximately $0.1 \mathrm{~g}$ of wet mucosal tissue was suspended in $1.0 \mathrm{~mL}$ of buffer $(100 \mathrm{mM}$ Dmannitol, $1 \mathrm{mM}$ Tris-HEPES, $\mathrm{pH} 7.5$ ), homogenized for $1 \mathrm{~min}$, and then centrifuged at $3000 \times g$ for $10 \mathrm{~min}$. The supernatant was assayed for sucrase and lactase according to the method described by Dahlquist (19). Enzyme activity was expressed as $\mathrm{nmol}$ substrate hydrolyzed $/ \mathrm{mL}$ protein $\cdot \mathrm{min}^{-1}$.

Statistics. Multiple comparisons of group means were performed using Tukey's method on the different groups after performing repeated measurements analysis of variance procedure between the groups (SAS Institute, Cary, NC) (28). Kinetic data were analyzed using the covariance technique (analysis of covariance). Data are represented as mean \pm SD unless otherwise noted.

\section{RESULTS}

The characteristics of the piglets used in the experiment are shown in Table 1. There were no differences in age, initial weight, or dietary intake among the three groups. Daily blood glucose levels as measured by Chemstrip BG were significantly higher for the DEX group as compared to the control group $(t=4.09$, $p=0.026$ ) (Fig. 2). The groups did not differ in urine glucose and volumes, which were monitored to help assess glycemia status. This is consistent with previous studies, which found the glucose renal threshold for $3-$ to $53-\mathrm{kg}$ piglets to be 8.0 to 9.5 $\mathrm{mM}(29)$. One pig in the DEX-treated group was an outlier $(>2$ SD from the mean) for blood and urine glucose levels as well as for velocity of zinc transport. Because of these extreme biologic variations, this pig was excluded from the data analysis.

Periodic sucrase assays before and after the BBMV preparation produced $10 \pm 2.5$-fold increases in sp act. The experiments for method development showed that the BBMV concentration and the amount of radioactive zinc used were optimal for the sensitivity and precision of the zinc transport studies. The EadieHofstee plot regression curves for individual studies had correlation coefficients in the range of 0.70 to 0.99 .

No significant differences were detected in the kinetic parameters of zinc transport among the proximal, medial, and distal sections of the small intestine (data not shown). Duodenal transport was not measured because an insufficient amount of mucosa was available from this segment.

Figure 3 shows saturation curves comparing the initial rate of zinc uptake by BBMV for the three groups. The values for the DEX-treated group were higher than the control and high zinc diet group at each extravesicular zinc concentration. There was no difference in zinc uptake velocities between high zinc and control groups. The Eadie-Hofstee plots of the three groups are shown in Figure 4, in which the data are presented as the means of each group. $\mathbf{J}_{\max }$ and $\mathrm{Km}$ values were calculated from linear regression analysis of these plots. The $y$-intercept of the regression equation represents the $J_{\max }$ and the absolute value of the slope represents the $\operatorname{Km}(23,24)$. This figure shows that the DEXtreated group not only had a $170 \%$ higher $\mathrm{J}_{\max }$ but also an $80 \%$ higher $\mathrm{Km}$ than the other two groups.

The amount of ${ }^{65} \mathrm{Zn}$ loaded in BBMV after a 60 -min incubation was greater in DEX than in control piglets $(5.24 \pm 0.92$ $\mu \mathrm{mol} / \mathrm{mg}$ protein versus $4.64 \pm 0.48 \mu \mathrm{mol} / \mathrm{mg}$ protein) but the difference was not statistically significant. The zinc efflux rate was much higher in control piglets than in DEX piglets (Fig. 5). After a 0.5 -min efflux, there was $31.0 \%$ of ${ }^{65} \mathrm{Zn}$ left in BBMV of DEX-treated pigs, whereas there was only $7.2 \%$ of loaded ${ }^{65} \mathrm{Zn}$ in BBMV of the control animals $(p<0.001)$. After a 5 -min efflux, there was still $17.9 \%$ of ${ }^{65} \mathrm{Zn}$ left in BBMV of DEXtreated animals compared with $3.6 \%$ in BBMV of control animals $(p<0.05)$. Compared with the amount of ${ }^{65} \mathrm{Zn}$ loaded at $4^{\circ} \mathrm{C}$, there was $21.5 \%$ more ${ }^{65} \mathrm{Zn}$ loaded in BBMV after a 60 min incubation at $37^{\circ} \mathrm{C}(p<0.05)$.

Similar levels of plasma zinc were found among the three groups. Furthermore, there were no differences in liver and intestinal mucosal zinc content between the DEX-treated and control groups. However, the high zinc diet group did have a significantly higher zinc content in both liver and intestinal mucosa than the other two groups (Fig. 6).

Liver and intestinal MT concentrations are shown in Table 2. High zinc-fed piglets had a 2 - to 10 -fold higher liver MT concentration than those in the other two groups. There were no significant differences in MT concentration in intestinal mucosa among the treatment groups.

Figure 7 shows representative protein separations in mucosal samples from the three treatment groups after separation by the FPLC system. As can be seen, there are no major zinc or copper peaks in the control piglets at $20 \mathrm{~d}$. In the DEX animals (Fig. $7 B$ ), two major zinc peaks are observed, one in the elution sample representative of an intermediate molecular mass (30-60 $\mathrm{kD})$ and the other with lower molecular mass (5-10 kD). The latter peak coincided with a copper peak, which was not observed in control animals. Zinc-treated animals exhibited three zinc peaks; one with a high molecular mass $(>200 \mathrm{kD})$ and the other two with molecular masses similar to those observed in the DEX animals. The low molecular mass peak, however, was substantially larger in this group. No distinct copper peaks were observed in these animals. 
Table 1. Characteristics of piglets*

\begin{tabular}{lccccc}
\hline & Age $(\mathrm{d})$ & $\begin{array}{c}\text { Initial } \\
\text { weight } \\
(\mathrm{kg})\end{array}$ & $\begin{array}{c}\text { Formula } \\
\text { consumed } \\
\left(\mathrm{mL} / \mathrm{kg} \cdot \mathrm{d}^{-1}\right)\end{array}$ & $\begin{array}{c}\text { Weight gain } \\
(\mathrm{g} / \mathrm{d})\end{array}$ & $\begin{array}{c}\text { Urine volume } \\
\left(\mathrm{mL} / \mathrm{kg} \cdot \mathrm{d}^{-1}\right)\end{array}$ \\
\hline Control $(n=7)$ & $13.9 \pm 0.4$ & $3.62 \pm 0.34$ & $360 \pm 35$ & $85 \pm 50$ & $115 \pm 35$ \\
DEX $(n=6)$ & $14.0 \pm 0.8$ & $3.68 \pm 0.29$ & $385 \pm 30$ & $51 \pm 42$ & $145 \pm 45$ \\
High $\operatorname{cinc}(n=7)$ & $13.9 \pm 0.7$ & $3.44 \pm 0.24$ & $355 \pm 75$ & $88 \pm 52$ & $130 \pm 40$ \\
\hline
\end{tabular}

* Values are expressed as mean $\pm \mathrm{SD}$.

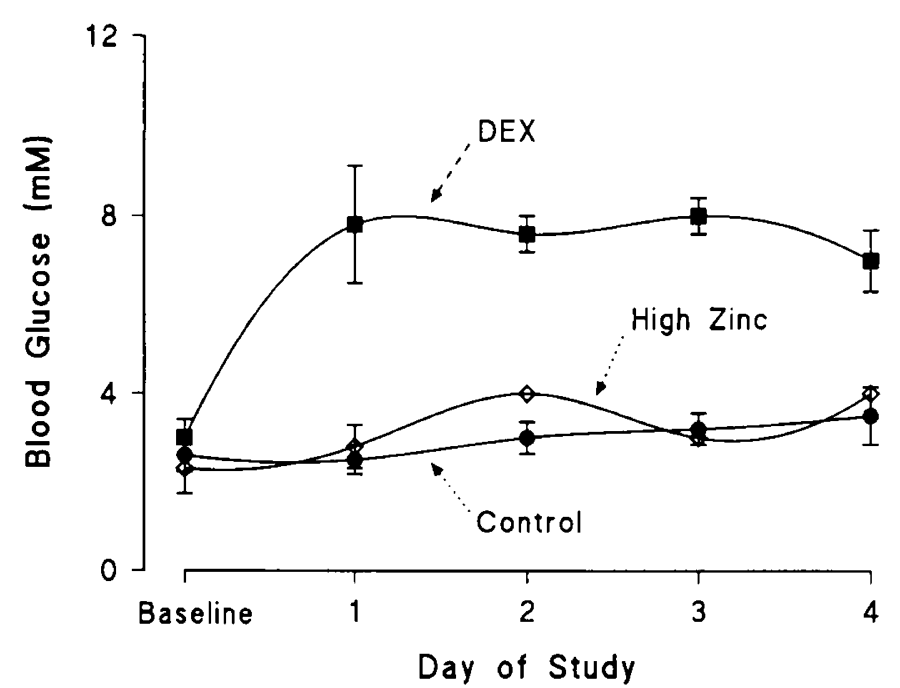

Fig. 2. Daily blood glucose values measured at baseline and on each day of treatment. Data represent means \pm SD.

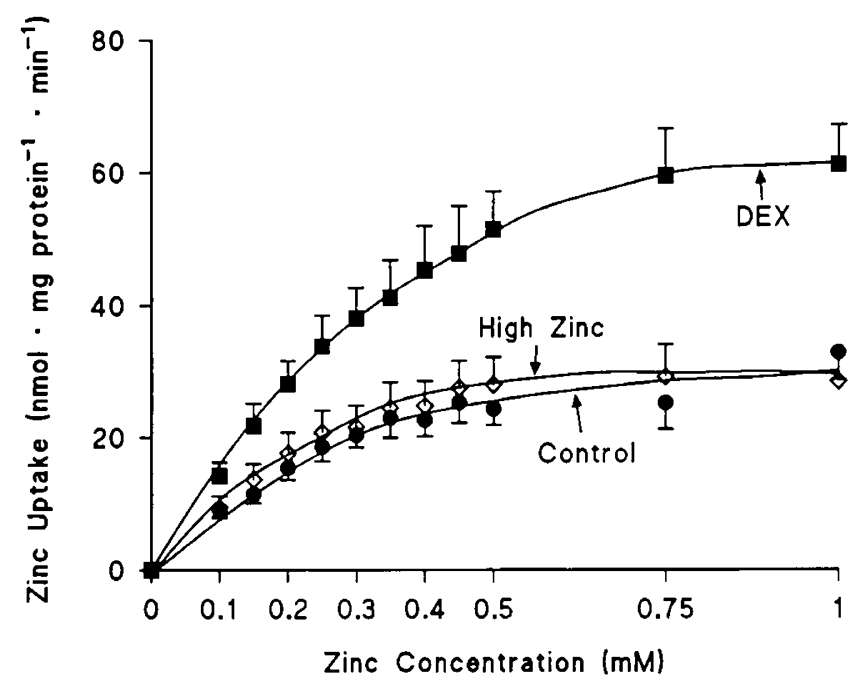

Fig. 3. Initial rates of $\mathrm{Zn}^{2+}$ uptake ( $1 \mathrm{~min}$ ) by BBMV with extravesicular $\mathrm{Zn}^{2+}$ concentrations ranging from 0 to $0.50 \mathrm{mM}$. Data represent the mean $\pm S E M$ for vesicles from seven control piglets. seven piglets fed a high zinc diet $(15.3 \mathrm{mmol} / \mathrm{kg})$. and six DEX-treated piglets $(1.5 \mathrm{mg} / \mathrm{kg}$ intramuscularly, twice a day, and $4.0 \mathrm{mg} / \mathrm{mL}$ ).

Table 3 presents the results of intestinal lactase and sucrase activity from homogenates of the mucosal scrapes. Although there were no statistically significant differences among the three groups, the DEX-treated group tended to have lower lactase activity and higher sucrase activity than the other two groups ( $p$ $=0.18$ and $p=0.12$, respectively).

\section{DISCUSSION}

In this study, exogenous DEX given to developing piglets resulted in higher zinc influx and reduced zinc efflux across intestinal brush border membrane. which is suggestive of induc-

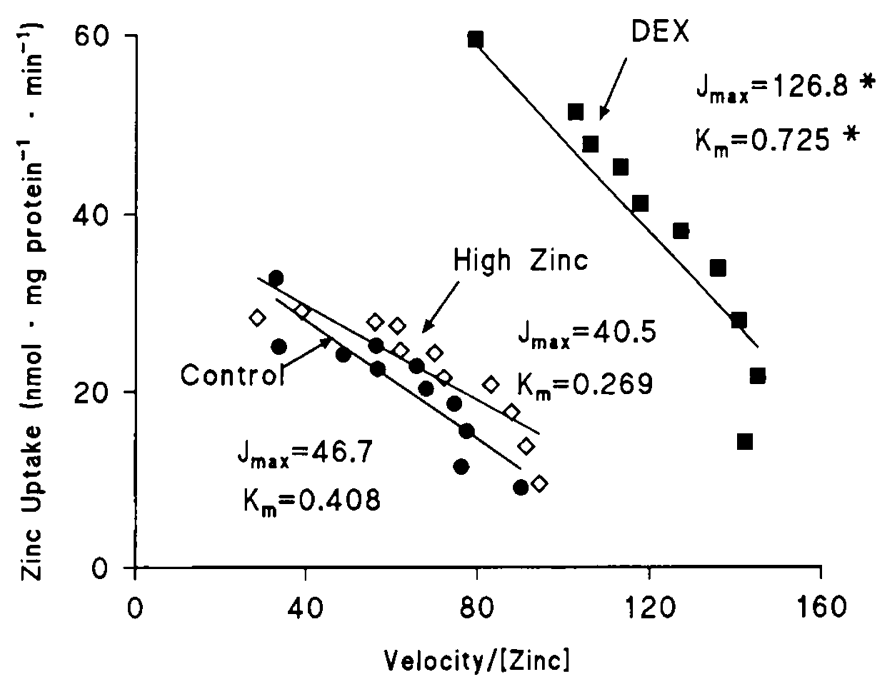

Fig. 4. Eadie-Hofstee plot of the kinetics of $\mathrm{Zn}^{2+}$ uptake by BBMV from the data described in Figure 2. Data are expressed as initial rates of uptake ( $1 \mathrm{~min}$ ). $\boldsymbol{J}_{\max }$ and $\mathrm{Km}$ for each group were determined from linear regression equations and are expressed as nmol zinc/mg total protein. $\min ^{-1}$ and $\mathrm{mM}$, respectively. ${ }^{*}$. Significantly different values $(p<0.05)$.

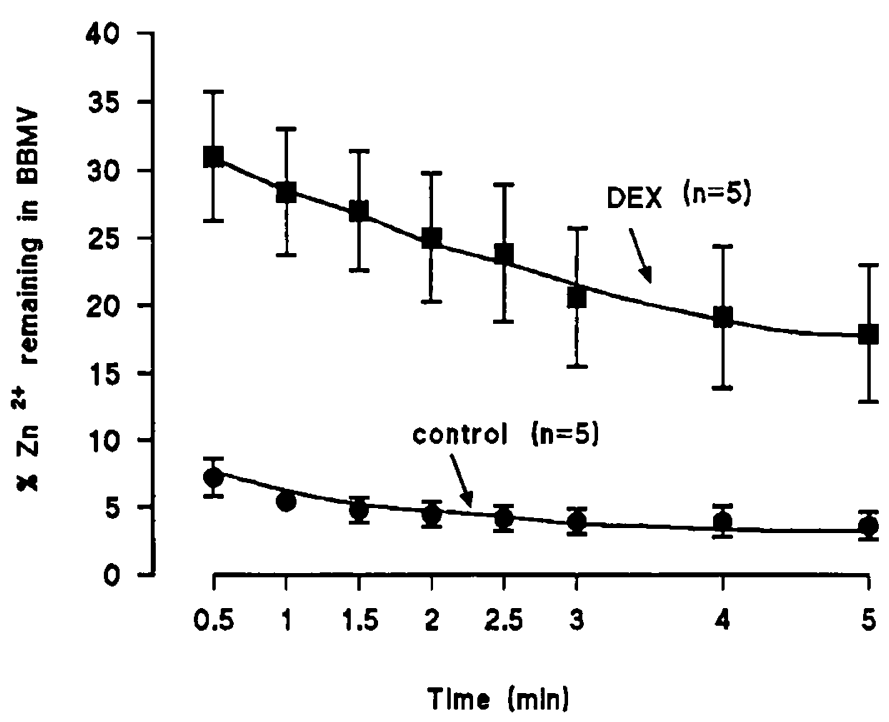

Fig. 5. The effect of DEX treatment on $\mathrm{Zn}^{2+}$ efflux from BBMV preloaded with $\mathrm{Zn}^{2+}$. Time 0 represents the amount of $\mathrm{Zn}^{2+}$ taken up by BBMV during preloading (i.e. $100 \% \mathrm{Zn}^{2+}$ remaining in BBMV). Each point is the mean $( \pm \mathrm{SEM})$ of five piglet samples.

tion of maturation of intestinal epithelial cells. Five $d$ of DEX treatment produced a significantly higher $\mathrm{J}_{\max }$ for zinc uptake. Compared with controls, this implies greater quantities of zinc carrier protein in the brush border membrane, possibly as a result of up-regulated protein synthesis or prolonged half-life of the protein in the membrane. The higher $\mathrm{Km}$ observed with DEX treatment may also reflect a lower affinity of the carrier protein for zinc.

Another possible mechanism to explain the increased zinc 


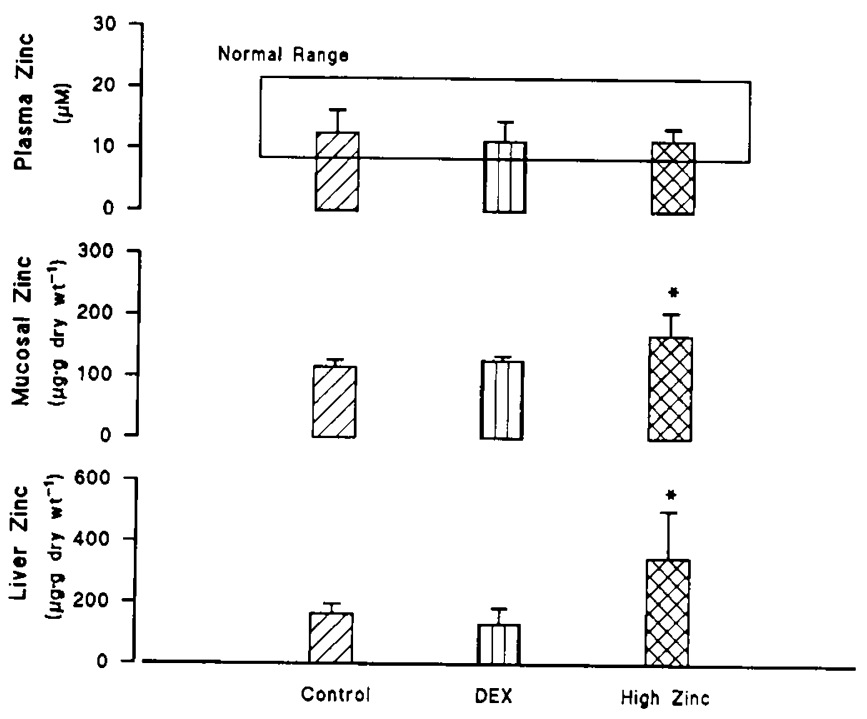

Fig. 6. Comparisons of plasma. mucosal, and liver zinc values between treatment groups. Bars represent mean \pm SD for tissue from seven control piglets, six DEX-treated piglets $\left(3.0 \mathrm{mg} / \mathrm{kg} \cdot \mathrm{d}^{-1}\right.$ and $\left.4.0 \mathrm{mg} / \mathrm{mL}\right)$, and seven piglets fed a high zinc diet $(15.3 \mathrm{mmol} / \mathrm{kg})$. The normal range for plasma zinc was determined in piglets up to $3 \mathrm{wk}$ old by Ullrey et al. (30). *. Significantly different groups $(p<0.05)$.

Table 2. Tissue MT concentrations*

\begin{tabular}{lcc}
\hline & $\begin{array}{c}\text { Liver } \\
\text { (nmol/g tissue) }\end{array}$ & $\begin{array}{c}\text { Intestinal mucosa } \\
\text { (nmol/g tissue) }\end{array}$ \\
\hline Control $(n=7)$ & $7.1 \pm 2.0$ & $4.5 \pm 1.1$ \\
DEX $(n=6)$ & $7.1 \pm 1.6$ & $3.7 \pm 1.7$ \\
High zinc $(n=7)$ & $79.0 \pm 28.6 \dagger$ & $4.6 \pm 2.3$ \\
\hline
\end{tabular}

* Values are expressed as mean $\pm \mathrm{SD}$.

$\dagger p<0.001$.

transport is that DEX inhibits PG synthesis in small intestinal enterocytes. Such a mechanism has been proposed for the improvement of respiratory parameters by DEX treatment in premature infants treated for chronic lung disease (31). Song et al. (32) suggested that $\mathrm{PGE}_{2}$ chelates zinc at the intestinal lumen and carries it across the mucosal cell of the small intestine. However, it should be noted that the concentration of PG used was considerably lower than that of zinc transported, making it unlikely that a quantitative effect via chelation of zinc occurred. In contrast, Cousins et al. (33) and Cunnane (34) reported that physiologic doses of $\mathrm{PGF}_{2}$ inhibited zinc absorption. Differences in PG dose and location of treatment could account for the conflicting results.

The observed similar levels of plasma, intestinal mucosa, and liver zinc between DEX and control groups suggested no differences in net transfer of zinc across the intestine. Bonewitz et al. (7) found that DEX-treated adult rats had a $75 \%$ higher lumen to mucosa transport of zinc and a $45 \%$ lower mucosa to plasma transport; thus, part of the transported zinc was retained in the mucosa cells. In rats given a bolus or a daily injection of DEX for $7 \mathrm{~d}$, overall zinc absorption was not increased by DEX, but an accumulation of zinc in small intestinal mucosa was found (35). The failure of our DEX-treated piglets to accumulate zinc in intestinal mucosa may be the result of immaturity of their intestinal mucosa compared with the chronologically older animals previously studied (35). High permeability of the brush border membrane could have allowed the leakage of the zinc from mucosal cells back into the intestinal lumen in the piglets. However, based on the efflux experiment, the permeability of BBMV to zinc in DEX-treated piglets was much lower than that in the control piglets. These results are consistent with previous observations of glucocorticoid-induced inhibition of calcium transport by a reduction in permeability of the intestinal mucosa
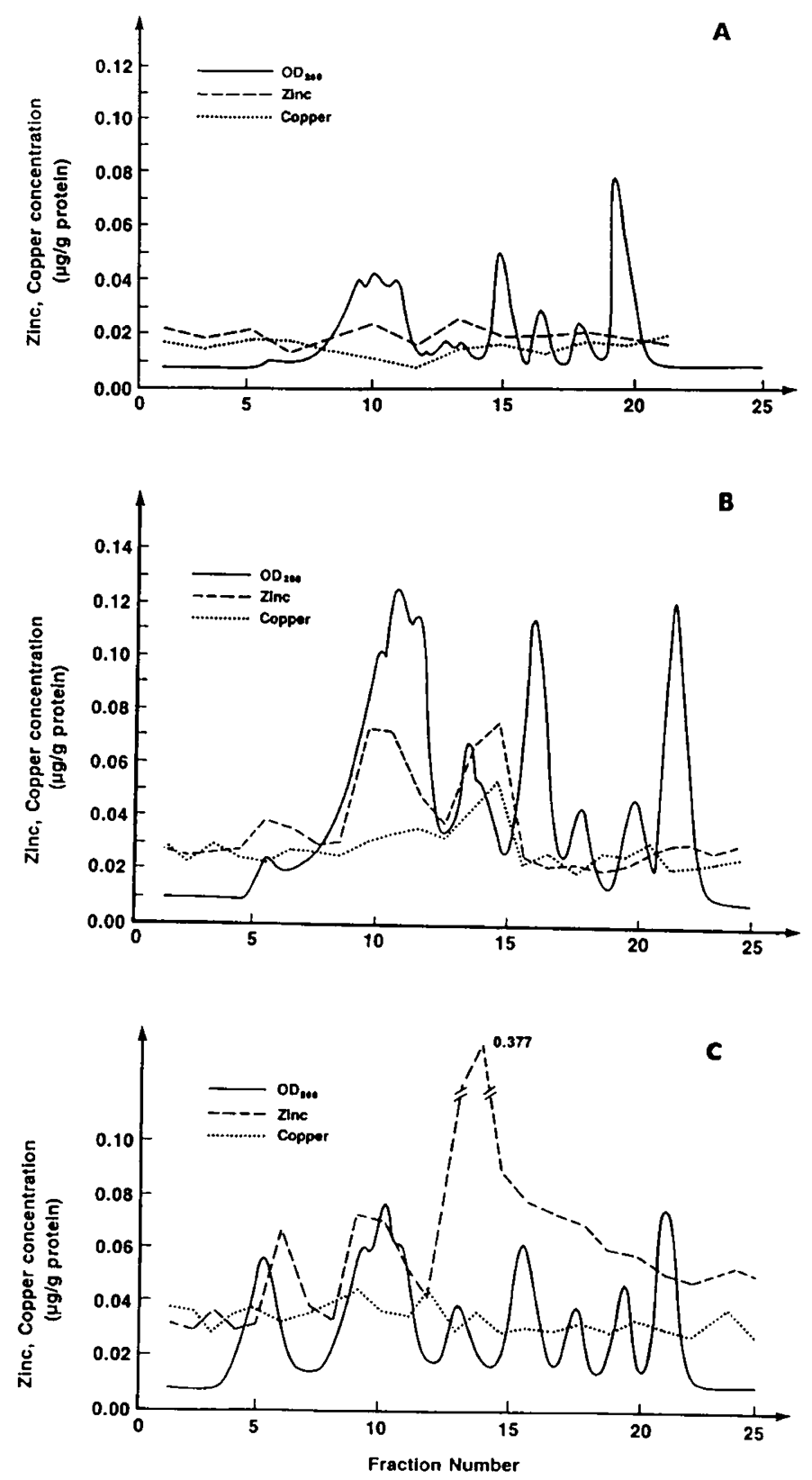

Fig. 7. FPLC gel filtration chromatography of mucosal homogenates ( $20 \% \mathrm{wt} / \mathrm{vol}$ ) on Superose 12 in $20 \mathrm{mM}$ HEPES-PBS buffer at $\mathrm{pH} 7.4$ Flow rate was $60 \mathrm{~mL} / \mathrm{h}$ and a $500-\mu \mathrm{L}$ sample was injected. $A$, a control animal; $B$, a DEX-treated animal; and $C$, a high zinc-treated animal.

Table 3. Brush border enzyme activity*

\begin{tabular}{lrr}
\hline & Sucrase & \multicolumn{1}{c}{ Lactase } \\
& \multicolumn{1}{c}{$(\mathrm{U})$} & \multicolumn{1}{c}{$(\mathrm{U})$} \\
\hline Control $(n=7)$ & $66.7 \pm 34.7$ & $228.2 \pm 51.1$ \\
DEX $(n=6)$ & $100.3 \pm 35.8$ & $85.2 \pm 28.6$ \\
High zinc $(n=7)$ & $74.0 \pm 22.4$ & $122.6 \pm 56.2$ \\
\hline
\end{tabular}

* Values are expressed as mean \pm SD. U. nmol substrate hydrolyzed/ $\mathrm{mg}$ total protein $\cdot \mathrm{min}^{-1}$.

of 14-d-old rats (36). Furthermore, glucocorticoid treatment in rats of the same age can cause premature "closure" of the small intestine (37). The higher influx and lower efflux of zinc across intestinal brush border membranes plus lack of zinc accumulation in the intestinal mucosa suggests that DEX enhances zinc absorption by a carrier-mediated mechanism (38). Possible explanations for the unchanged plasma and tissue zinc levels may be the moderate zinc content of the pig formula. the short 
duration of DEX treatment, and/or the higher zinc efflux in mucosal membranes of DEX-treated animals. These possible mechanisms need to be clarified in future studies.

In the present study, DEX did not induce MT synthesis in liver or intestine. which is partially different from the results of Hempe et al. (35); they found that intraperitoneal administration of DEX to rats for $7 \mathrm{~d}$ markedly increased liver MT synthesis over control animals but did not alter intestinal MT concentration. Zlotkin and Cherian (39) found that hepatic MT levels were highest in the human premature infants and decreasing during the first year of life. In unpublished data from our laboratory, a marked decrease in liver MT concentration was observed during the first $20 \mathrm{~d}$ of life in piglets with and without DEX treatment. Compared with liver MT, the level of intestinal MT changed very little in the same period. These data suggest that the physiologic decrease in liver MT is not altered by DEX therapy.

To determine if exogenous DEX caused induction of other proteins located in the brush border membrane, we measured lactase and sucrase activities. In newborn rats, mucosal lactase activity declines to adult levels by $4 \mathrm{wk}$ postnatally (40), but in the presence of exogenous glucocorticoids at a much higher dose $(75 \mathrm{mg} / \mathrm{kg})$ a reduction in lactase activity occurred around $3 \mathrm{wk}$ postnatally. possibly due to DEX-induced maturation of the intestine. We observed a trend $(p=0.18)$ that indicated a reduced (28\%) lactase activity in the DEX-treated versus control animals. The ontogeny of the increase in sucrase activity during early maturation of the small intestine can also be induced by exogenous glucocorticoids (41). We observed a $34 \%$ higher sucrase activity in the DEX-treated compared with the control animals $(p=0.12)$. Because there was no sucrose present in the piglet diet, the suggested induction of sucrase may be attributed to the presence of glucocorticoids. Neither lactase nor sucrase activities were altered in animals fed the high zinc diet compared with the activities in the control animals.

The short course of DEX used in this study produced two outcomes often experienced clinically in DEX-treated infants with bronchopulmonary dysplasia. DEX-treated piglets had significantly higher blood glucose levels than the other two groups. as shown in infants (2). Furthermore, the DEX-treated group of piglets had a lower mean weight gain than the other two groups; however, these differences were not statistically significant, perhaps because of type II error. Growth delay has been associated with DEX therapy in infants treated for bronchopulmonary dysplasia (2) and in the newborn rat model (42).

A 5-d high zinc intake did not change the kinetic parameters of zinc transport, but the significantly higher liver and intestinal mucosal zinc and liver MT in this group compared with the control group suggest that more zinc was transported across the brush border membrane and entered the systemic circulation. The recent study by Hunt $e t$ al. (43) in rats supports this finding. In their study, a 4-d moderately high zinc feeding $[2.2 \mathrm{mmol}$ $(141 \mathrm{mg}) / \mathrm{kg}$ dry weight of diet] led to overall reduced zinc absorption compared with the same period of feeding with lower dietary zinc $[(0.2 \mathrm{mmol}(11.2 \mathrm{mg}) / \mathrm{kg}$ dry weight or diet $]$. The similar zinc transport kinetics we found between high zinc and control piglets may suggest that passive diffusion of zinc is the principal mode of mucosal transport in early neonatal life. The unchanged rate of zinc transport across BBMV and lack of induction of intestinal MT concentration will allow more dietary zinc to be absorbed in the condition of high dietary zinc.

Comparing the three FPLC graphs, the pattern of protein peaks are similar with the exception that peaks are notably higher for the DEX-treated piglet than for the other two treatment groups. This is consistent with the report that DEX can induce several enzymes and increase the RNA to DNA ratio in intestinal mucosa (44). Because MT was not induced in intestinal mucosa of all piglets, the change in the height of zinc and copper peaks suggested that several zinc and copper binding proteins other than MT were induced by DEX and high zinc feeding. It is possible that the low molecular mass protein is the cysteine-rich protein, which recently has been shown to bind zinc in small intestinal cytosol (45). Luminal zinc concentration was found to be a stronger inducer of cysteine-rich protein expression than DEX treatment (46).

We conclude that DEX treatment can induce several enzymes and proteins in apical membranes of small intestinal enterocytes in early weaned piglets. As a result, zinc influx across the brush border membrane was enhanced and zinc efflux across the membrane was decreased. The similar kinetic parameters found in the zinc transport study between high dietary zinc and control piglets suggests that a high zinc intake decreases overall zinc absorption via a mechanism other than at the level of carriermediated zinc transport across the brush border membrane. The excess dietary zinc in young animals probably results in high mucosal passive diffusion of zinc, with cytosolic MT playing a limited role in regulation of zinc absorption.

Because of the wide range of biologic effects of glucocorticoids. DEX treatment in LBW infants with chronic lung disease can cause both beneficial effects (1-3) and harmful effects, including pulmonary infection, hyperglycemia, hypertension, retarded growth, and bone demineralization $(2,47)$.

Our interest is in knowing the impact of the therapeutic use in LBW infants of exogenous glucocorticoids on induction of maturation of intestinal enterocytes that in turn may alter regulatory mechanisms for trace element transport. It is conceivable that DEX therapy in very premature infants may induce maturation of the small intestine and possibly the synthesis or activity of zinc carrier protein(s) on the brush border membrane. Other possible mechanisms to explain the observed changes in zinc transport associated with DEX treatment are a change in lipid composition of the membrane and/or altered binding of zinc to the membranes. Additional research is required to elucidate the mechanism of DEX-induced zinc uptake and the possible clinical relevance to zinc homeostasis in the LBW infants who receive chronic therapy with this drug to ameliorate the outcomes of chronic lung disease.

\section{REFERENCES}

1. Cummings JJ, D'Eugenio DB. Gross SJ 1989 A controlled trial of dexameth asone in preterm infants at high risk for bronchopulmonary dysplasia. $N$ Engl J Med 320:1505-1510

2. Yeh TF. Torre JA. Rastogi A. Anyebuno MA. Pildes RS 1990 Early postnatal dexamethasone therapy in premature infants with severe respiratory distress syndrome:a double-blind, controlled study. J Pediatr 117:273-282

3. Kazzi NJ, Brans YW, Poland RL 1990 Dexamethasone effects on the hospital course of infants with bronchopuimonary dysplasia who are dependent on artificial ventilation. Pediatrics 86:722-727

4. Shaw JCL 1979 Trace elements in the fetus and young infant. I. Zinc. Am J Dis Child 133:1260-1268

5. Hambidge KM. Casey CE 1981 Trace element requirements in premature infants. In: I ebenthal E (ed) Textbook of Gastroenterology and Nutrition in Infancy. Raven Press, New York, pp 595-610

6. Atkinson SA. Shah J 1991 Calcium and phosphorus fortification of preterm formulas:drug-mineral and mineral-mineral interactions. In: Hillman L (ed) Mineral Requirements for the Premature Infant. Wyeth Ayerst Vutritional Seminar Series. Vol 2, No 1. Excerpta Medica. Princeton. NJ. pp $58-75$

7. Bonewitz Jr RF, Foulkes EC. O'Flaherty EJ. Hertzberg VS 1983 Kinetics of zinc absorption by the rat jejunum:effects of adrenalectomy and dexamethasone. Am J Physiol 244:G314-G320

8. Menard PM. Oestricher P. Cousins RJ 1983 Zinc transport by isolated vascularly perfused rat intestine and brush border vesicles. In: Inglett GC (ed) Nutritional Bioavailability of Zinc. American Chemical Society, Washington. DC. pp 233-246

9. Cousins RJ 1985 Absorption. transport and hepatic metabolism of copper and zinc:special reference to metallothionein and ceruloplasmin. Physiol Res 65:238-309

10. Richards MP. Cousins RJ 1975 Mammalian zinc homeostasis:requirement for RNA and metallothionein synthesis. Biophys Res Commun 64:1215-1223

11. Cousins RJ. Leinart AS 1988 Tissue-specific regulation of zinc metaholism and metallothionein genes by interleukin 1. FASEB J 2:2884-2890

12. Flanagan PR. Haist J. Valberg LS 1983 Zinc absorption. intraluminal zinc and intestinal metallothionein levels in zinc-deficient and zinc-repleted rodents. J Nutr 113:962-972

13. Pattison SE. Cousins RJ 1986 Kinetics of zinc uptake and exchange hy primary cultures of rat hepatocytes. Am J Physiol 250:E677-E685

14. Cousins RJ. Dunn MA. Leinart AS. Yedinak KC. DiSilvestro RA 1986 
Coordinate regulation of zinc metabolism and metallothionein gene expression in rats. Am J Physiol 251:E688-E694

15. Cooper JE 1975 The use of the pig as an animal model to study problems associated with low birthweight. Lab Anim 9:337-343

16. National Research Council 1984 Guide for the Care and Use of Experimental Animals. Institute of Laboratory Animal Resources of the National Research Council, Vol 2. National Institutes of Health publication No. 85-23 (rev). Washington, DC

17. Deleted in proof

18. Kramer Ll. Hultzen C 1978 The role of steroids in early bronchopulmonary dysplasia (BPD). Pediatr Res 12:564A(abstr)

19. Dahlquist A 1968 Assay of intestinal disaccharidases. Anal Biochem 22:99107

20. Davidson LA, Lonnerdal B 1988 Specific binding of lactoferrin to brush border membrane:ontogeny and effect of glycan chain. Am J Physiol 254:G580G585

21. Menard PM. Cousins RJ 1983 Zinc transport by brush border membrane vesicles from rat intestine. J Nutr !13:1434-1442

22. Bradford MM $1976 \mathrm{~A}$ rapid and sensitive method for the quantitation of microgram quantities of protein utilizing the principle of protein-dye binding. Anal Biochem 72:254-260

23. Eadie GS 1942 The inhibition of cholinesterase by physostigmine and prostigmin. J Biol Chem 146:85-93

24. Hofstee GHJ 1952 On the evaluation of the constants $\mathrm{Vm}$ and $\mathrm{Km}$ in enzyme reactions. Science 116:329-331

25. Zivin JA. Waud DR 1982 How to analyze binding. enzyme and uptake data:the simplest case, a single phase. Life Sci 30:1407-1422

26. Beatty RD 1978 Concepts, instrumentation and techniques in atomic absorption spectrophotometry. Perkin-Elmer Corporation. Norwalk. CT

27. Eaton DL. Toal BF 1982 Evaluation of the $\mathrm{CD} /$ hemoglobin affinity assay for the rapid determination of metallothionein in biological tissues. Toxicol Appl Pharmacol 66:134-142

28. SAS Institute 1985 SAS User's Guide:Statistics, Version 5. SAS Institute, Cary, NC, pp 113-138

29. Link RP 1953 A study of the effect of repeated intraperitoneal injections of glucose in pigs. Am J Vet Res 14:150-159

30. Ullrey DE, Brent BE, Hoefer JA, Miller ER, Bradley BL 1967 Swine hematology from birth to maturity. IV. Serum calcium, magnesium, sodium, potassium, copper, zinc and inorganic phosphorus. J Anim Sci 26:1024-1029

31. Mammel MC. Green TP. Johnson DE, Thompson JT 1983 Controlled trial of dexamethasone therapy in infants with bronchopulmonary dysplasia. Lancet $1: 1.356-1.357$

32. Song MK, Lee DBN, Adham NF 1988 Influence of prostaglandin on unidirectional zinc fluxes across the small intestine of the rat. Br J Nutr 59:417-428

33. Cousins RJ. Smith KT. Failla ML, Markowitz LA 1978 Origin of low molecular weight zinc-binding complexes from rat intestine. Life Sci 23:1819-1826

34. Cunnane SC 1982 Maternal essential fatty acid supplementation increases zinc absorption in neonatal rats:relevance to the defect in zinc absorption in acrodermatitis enteropathica. Pediatr Res 16:599-603

35. Hempe JM. Carlson JM. Cousins RJ 1991 Intestinal metallothionein gene expression and zinc absorption in rats are zinc-responsive but refractory to dexamethasone and interleukin la. J Nutr 121:1389-1396

36. Ghishan FK. McNeely RL 1982 Intestinal maturation:the effect of glucocorticoids on in vivo net magnesium and calcium transport in the rat. Life Sci 31:133-138

37. Daniels VG. Hardy RN. Malinowska KW. Nathanielsz PW 1973 The influence of exogenous steroids on macromolecule uptake by the small intestine of the newborn rat. J Physiol 229:681-695

38. Hoadley JE. Cousins RJ 1988 Regulatory mechanisms for intestinal transport of zinc and copper. In: Prasad AS. Brewer GJ (eds) Trace Elements Research in Humans. Alan R Liss. New York. pp 141-155

39. Zlotkin SH, Cherian MG 1988 Hepatic metallothionein as a source of zinc and cysteine during the first year of life. Pediatr Res 24:326-329

40. Majumdar APN. Rehfeld JF 1983 Effect of hydrocortisone on gastrin cell function in various tissues of suckling rats. Digestion 27:165-173

41. Majumdar APN, Nielson H 1985 Influence of glucocorticoids on prenatal development of the gut and pancreas in rats. Scand J Gastroenterol 20:6571

42. Venkataraman PS, Shankararao R, Chari G, Vidyasagar D 1991 Effects of steroids on growth and bone mineralization in the postnatal period. Pediatr Res 29:58A(abstr)

43. Hunt JR, Johnson PE. Swan PB 1981 Effect of dietary zinc on ${ }^{\text {ts }} \mathrm{Zn}$ absorption and turnover in rats. Nutr Res 9:161-171

44. Neu J, Crim WN, Hodge NC 1986 Comparative effects of glucocorticoids and prostaglandins on small intestine of infant rats. Pediatr Res 20:109-112

45. Hempe JM, Cousins RJ 199 ] Cysteine-rich intestinal protein binds zinc during transmucosal zinc transport. Proc Natl Acad Sci 88:9671-9674

46. Levenson CW, Shay NF. Cousins RJ 1992 Regulation of cysteine-rich intestinal protein in RNA levels by dexamethasone in the developing rat intestine. FASEB J 6:A881(abstr)

47. Taeusch HW 1975 Glucocorticoid prophylaxis for respiratory distress syndrome:a review of potential toxicity. J Pediatr 87:617-623 